\title{
Vibrio alginolyticus gyrB sequence analysis and gyrB-targeted PCR identification in environmental isolates
}

\author{
Peng Luo, Chaoqun $\mathrm{Hu}^{*}$
}

South China Sea Institute of Oceanology, Chinese Academy of Sciences, 164 West Xingang Road, Guangzhou 510301, PR China

\begin{abstract}
B fragments (about $1.2 \mathrm{~kb}$ ) of 9 Vibrio alginolyticus strains were sequenced, and their phylogenetic relationship with other closely related Vibrio species was analyzed. All the $V$. alginolyticus strains grouped into one strongly supported cluster in the phylogenetic tree. There were 54 base variations among the $1167 \mathrm{bp}$ mutual gyrB regions of $11 \mathrm{~V}$. alginolyticus strains; all the $\mathrm{V}$. alginolyticus strains shared the same amino acid sequence except $V$. alginolyticus ATCC 17749. Based on the gyrB sequences, we designed 2 primers for specific PCR identification of $V$. alginolyticus. Fifty-two bacterial strains from 12 genera were used to test the PCR specificity, and only $V$. alginolyticus strains produced the predicted $568 \mathrm{bp}$ amplification fragment. In addition, PCR screening of 50 randomly selected environmental strains, grown on thiosulfate citrate bile salts-sucrose (TCBS) medium, gave rise to a positive amplification result for $V$. alginolyticus from 37 of them. To further confirm accuracy of PCR identification, biochemical identification of the 50 strains was carried out. Strains giving positive PCR amplification were biochemically identified as $V$. alginolyticus, while strains that gave negative results were biochemically identified as other Vibrio or non-Vibrio species. Using the basic local alignment search tool (BLAST), gyrB sequences obtained from 2 randomly selected strains (YJ0666 and YJ167B) of the 37 PCR-positive strains showed highest identity values with $V$. alginolyticus strains $(>96 \%$ ). Thus, our results demonstrated that gyrB is a good marker for molecular identification of $V$. alginolyticus, and a gyrB-based PCR method was successfully developed.
\end{abstract}

KEY WORDS: gyrB $\cdot$ Vibrio alginolyticus $\cdot$ PCR identification

Resale or republication not permitted without written consent of the publisher

\section{INTRODUCTION}

Vibrio alginolyticus, of the family Vibrionaceae, is ubiquitous in marine and estuarine environments. $V$. alginolyticus has acquired increasing importance as some strains are pathogenic to humans as well as aquatic animals and have caused huge economic losses (Balebona et al. 1998, Daniels \& Shafaie 2000, Villamil et al. 2003, Liu et al. 2004). Conventionally, screening and identification of $V$. alginolyticus from environmental bacterial isolates depend on biochemical methods, and commercial identification systems are available. However, due to similar biochemical characteristics and phenotypic flexibility, misidentification of Vibrio species including $V$. alginolyticus has often been reported (Robert-Pillot et al. 2002, O'Hara et al. 2003, Thompson et al. 2004). Moreover, identification based on biochemical tests is time consuming and resource intensive. For these reasons, molecular methods are required in screening and routine identification of $V$. alginolyticus. PCR is a rapid and sensitive method for this goal.

Liu et al. (2004) have developed a 16S rRNA genebased PCR method for identification of Vibrio alginolyticus; however, high homology of the 16S rRNA gene in Vibrio spp. makes it difficult to reliably differentiate and detect members of Vibrio through targeting of this gene (Kita-Tsukamoto et al. 1993, Ruimy et al. 1994). For instance, $16 \mathrm{~S}$ rRNA gene sequences revealed $99.7 \%$ homology between $V$. parahaemolyti- 
cus and V. alginolyticus (Ruimy et al. 1994). We have theoretically tested specificity of 4 primers designed by Liu et al. (2004) using the basic local alignment search tool (BLAST, Altschul et al. 1990) in GenBank, and found that the primers also completely matched with 16S rRNA gene regions of many other Vibrio species. Therefore, the 16S rRNA gene is not suitable for PCR identification of $V$. alginolyticus. Subsequently, researchers established collagenase and dnaJ gene-targeted multiplex-PCR methods for simultaneous identification of several Vibrio species including $V$. alginolyticus (Di Pinto et al. 2005, Nhung et al. 2007). In addition, a real-time PCR method has been developed for quantitative detection of $V$. alginolyticus (Zhou et al. 2007). However, multiplex-PCR requires strict reaction PCR conditions, and real-time PCR requires relatively expensive equipment and reagents. If the objective is just identification or screening of one bacterial species, traditional singleplex PCR is enough. Therefore, establishment of a reliable routine PCR method for extensive identification or screening of $V$. alginolyticus from environmental isolates is desirable.

The gyrB gene that encodes the B subunit protein of bacterial DNA gyrase has some superiorities for phylogenetic analysis and molecular identification: (1) it does not transfer horizontally among bacterial species; (2) the molecular evolution rate is higher than that of the 16S rRNA gene; (3) it has been found in most of bacterial species; and (4) it has both conserved regions and variable regions suitable for development of PCR primers (Yamamoto \& Harayama 1995, Venkateswaran et al. 1998, Fukushima et al. 2002). gyrB-targeted PCR methods have been developed for identification of bacteria from various genera including Vibrio (Kasai et al. 1998, Venkateswaran et al. 1998, Vuddhakul et al. 2000, Kumar et al. 2006, Thaithongnum et al. 2006, Zhou et al. 2007), Bacillus (Yamada et al. 1999), Pseudomonas (Yamamoto \& Harayama 1995, Izumi et al. 2007), Leptospira (Slack et al. 2006), Flavobacterium (Izumi et al. 2005), and Aeromonas (Sen 2005). These studies demonstrate the preferred choice of the $g y r B$ gene for molecular identification of closely related genomic species.

However, the high rate of molecular evolution of the gyrB gene also brings reservations about sequence heterogeneity of the gene among conspecific strains. There is no evidence that the same species always has highly similar or identical gyrB sequences. A report on molecular typing of Yersinia frederiksenii based on $g y r B$ sequence showed the existence of $g y r B$ sequence variability within the same species (Demarta et al. 2004). We compared the 2 gyrB sequences of Vibrio alginolyticus published in GenBank, and found that they were very different. Thus, it is necessary to com- pare multiple $g y r B$ sequences from $V$. alginolyticus before establishing a gyrB-targeted PCR method.

In the present study, we sequenced and analyzed partial gyrB sequences of 9 Vibrio alginolyticus strains from different origins, and based on these sequences, we developed a conventional PCR method for identification or screening of $V$. alginolyticus from environmental bacterial isolates.

\section{MATERIALS AND METHODS}

Bacterial strains, cultivation and DNA extraction. Bacterial strains were retrieved through purchase, donation or isolation from various environments (see Table 1). All Vibrio strains were overnight cultured in alkaline peptone water (APW) medium at $30^{\circ} \mathrm{C}$, and other bacterial strains were overnight cultured in the media recommended by the sellers or donators. Genomic DNA from the strains was extracted with the MiniBEST Bacterial Genomic DNA Extraction Kit (Takara Biotechnology) following the method provided by the manufacturer.

Sequencing and analysis of $\operatorname{gyr} B$ sequences of $\mathrm{Vib}$ rio alginolyticus. Fragments (about $1.2 \mathrm{~kb}$ ) of gyrB gene from $V$. alginolyticus ZJ0403, ZJ0428, ZJ0476, ZJ0479, ZJ0486, NA0419, NA0425, NA0426, and DX0406 were amplified with universal primers (UP1 and UP2r) as reported previously (Yamamoto \& Harayama 1995). Among them, V. alginolyticus ZJ0403, ZJ0428, ZJ0479, and ZJ0486 were isolated from juvenile or parent shrimp Litopenaeus vannamei in Zhanjiang, China; V. alginolyticus ZJ0476 was isolated from bay scallop Argopecten irradians concentricus in Zhanjiang, China; V. alginolyticus NA0419, NA0425, and NA0426 were isolated from different tissues of red drum Sciaenops ocellatus in Shenzhen, China; and V. alginolyticus DX0406 was isolated from seawater in Dongxing, China. PCR products were confirmed by agarose electrophoresis, purified, and directly sequenced using an Applied Biosystems 3730 Automatic Sequencer. Nine gyrB sequences retrieved and 2 gyrB sequences of $V$. alginolyticus (strains no. ATCC 17749 and 12G01) derived from GenBank (AF007288 and AAPS01000042) were aligned with the CLUSTAL-W program in the BioEdit package (Wang et al. 2007). Deduced amino acid sequences of $g y r B$ gene were also aligned with the CLUSTAL-W program in the BioEdit package. A neighbor-joining phylogenetic tree was constructed based on nucleic acid sequences using MEGA 3.1 software with a bootstrap test of 1000 replicates.

Species-specific primer design and PCR assay of Vibrio alginolyticus. A consensus gyrB sequence of the $11 \mathrm{~V}$. alginolyticus strains mentioned above was es- 
tablished after alignment with CLUSTAL-W program (see Fig. 1). Primer pairs that completely matched with the conservative region of the $g y r B$ sequences were designed, and the specificity of primers was theoretically tested by BLAST searches of the GenBank database. Finally, a pair of specific primers, AlgF1 and AlgR1, was established. The primer sequences were 5'-TCA GAG AAA GTT GAG CTA ACG ATT-3' (AlgF1, forward) and 5'-CAT CGT CGC CTG AAG TCG CTG T -3' (AlgR1, reverse). The AlgF1 and AlgR1 primers were predicted to amplify a $568 \mathrm{bp}$ fragment from $V$. alginolyticus gyrB gene. The PCR reaction was performed in $25 \mu \mathrm{l}$ volume containing $1 \mu \mathrm{l}$ genomic DNA, $0.4 \mu \mathrm{M}$ each primer, $2.5 \mu \mathrm{l} 10 \times$ PCR buffer, 2.0 $\mathrm{mM} \mathrm{Mg}{ }^{2+}, 0.2 \mathrm{mM} \mathrm{dNTP}$, and $1 \mathrm{U}$ Taq DNA polymerase (Takara Biotechnology). The amplification program consisted of an initial denaturation at $94^{\circ} \mathrm{C}$ for 4 min, 32 cycles of denaturation at $94^{\circ} \mathrm{C}$ for $30 \mathrm{~s}$, annealing at $64^{\circ} \mathrm{C}$ for $30 \mathrm{~s}$, extension at $72^{\circ} \mathrm{C}$ for $1 \mathrm{~min}$, and a final extension at $72^{\circ} \mathrm{C}$ for 8 min. After PCR amplification, $4 \mu \mathrm{l}$ of each product was added into a $1.0 \%$ agarose gel, electrophoresed, and followed by visualization under UV light.

Specificity of PCR for gyrB amplification of Vibrio alginolyticus. To test PCR specificity, 52 bacterial strains (including $16 \mathrm{~V}$. alginolyticus strains and 22 other Vibrio strains) from 12 genera were used (Table 1). PCR and electrophoresis were carried out as described above.

Strain identification from environmental bacterial isolates. Fifty bacterial strains isolated from farming seawater and marine animals in coastal areas of South China (see Table 2), grown on thiosulfate citrate bile salts-sucrose (TCBS) medium, were randomly chosen and overnight cultured in APW followed by DNA extraction. The aforementioned PCR was carried out with DNA templates from the 50 bacterial strains. For further confirmation of PCR specificity, biochemical identification of all 50 environmental bacterial strains was carried out by referring to the descriptions of the species listed in Bergey's Manual of Systematic Bacteriology (Brenner et al. 2005). In addition, fragments of gyrB gene of 2 randomly selected PCR-positive strains, YJ0666 and YJ167B, were amplified and sequenced according to the method described above. Similarity searches against GenBank entries were performed with the sequences acquired using the basic local alignment search tool (BLAST) algorithm in GenBank.

Nucleotide sequence accession numbers. The gyrB sequences of 9 original Vibrio alginolyticus strains and the 2 additional strains isolated from environmental samples, YJ0666 and YJ167B, were deposited in the GenBank database under the following accession numbers: EF579668-EF579676 and EF542801EF542802.
Table 1. Bacterial strains used in the present study. EN: isolated from the environment by our laboratory; APCCC: Aquatic Pathogen Collection Centre of China; CGMCC: Centre for General Microorganisms Collection of China; FJCDC: Fujian Centre for Disease Control and Prevention; ZSU: Zhongshan University; ATCC: American Type Culture Collection; SCSFI: South China Sea Fisheries Institute; BJCDC: Beijing Centre for Disease Control and Prevention; GDIM: Guangdong Institute of Microbiology

\begin{tabular}{|c|c|c|}
\hline Bacterial species & Strain no. & Source \\
\hline Vibrio alginolyticus & ZJ0403 & EN \\
\hline Vibrio alginolyticus & ZJ0428 & EN \\
\hline Vibrio alginolyticus & ZJ0476 & EN \\
\hline Vibrio alginolyticus & ZJ0479 & EN \\
\hline Vibrio alginolyticus & ZJ0486 & EN \\
\hline Vibrio alginolyticus & ZJ0451 & EN \\
\hline Vibrio alginolyticus & DX0406 & EN \\
\hline Vibrio alginolyticus & NA0419 & EN \\
\hline Vibrio alginolyticus & NA0425 & EN \\
\hline Vibrio alginolyticus & NA0426 & EN \\
\hline Vibrio alginolyticus & 0391 & APCCC \\
\hline Vibrio alginolyticus & 1.1587 & CGMCC \\
\hline Vibrio alginolyticus & HK8031 & FJCDC \\
\hline Vibrio alginolyticus & Z0504 & ZSU \\
\hline Vibrio alginolyticus & Z0505 & ZSU \\
\hline Vibrio alginolyticus & Z0515 & ZSU \\
\hline Vibrio parahaemolyticus & 17802 & ATCC \\
\hline Vibrio parahaemolyticus & 0302 & SCSFI \\
\hline Vibrio parahaemolyticus & Z0508 & ZSU \\
\hline Vibrio parahaemolyticus & 1.1614 & CGMCC \\
\hline Vibrio mimicus & 1.1969 & CGMCC \\
\hline Vibrio fluvialis & 1.1609 & CGMCC \\
\hline Vibrio nereis & 1.1623 & CGMCC \\
\hline Vibrio splendidus & 1.1606 & CGMCC \\
\hline Vibrio pelagius & 1.1588 & CGMCC \\
\hline Vibrio vulnificus & 1.1758 & CGMCC \\
\hline Vibrio vulnificus & D0683 & EN \\
\hline Vibrio natriegens & 1.1594 & CGMCC \\
\hline Vibrio proteolyticus & 1.1826 & CGMCC \\
\hline Vibrio campbellii & 1.1597 & CGMCC \\
\hline Vibrio campbellii & 1.1598 & CGMCC \\
\hline Vibrio campbellii & DX0520 & EN \\
\hline Vibrio harveyi & 1.1593 & CGMCC \\
\hline Vibrio harveyi & NH0503 & SCSFI \\
\hline Vibrio harveyi & SD0613 & EN \\
\hline Non-O1 Vibrio cholerae & 06153 & BJCDC \\
\hline Non-O1 Vibrio cholerae & $\mathrm{SC} 0312$ & EN \\
\hline Vibrio furnissii & 33841 & ATCC \\
\hline Listonella anguillarum & 0387 & APCCC \\
\hline Listonella anguillarum & Z0512 & ZSU \\
\hline Pseudomonas fluorescens & 10646 & ATCC \\
\hline Pseudomonas aeruginosa & 1.50 & APCCC \\
\hline Aeromonas sobria & 0398 & APCCC \\
\hline Aeromonas hydrophila & 0388 & APCCC \\
\hline Edtardsiella tarda & $\mathrm{S} 1$ & APCCC \\
\hline Pseudoalteromonas sp. & GS0432 & EN \\
\hline Shewanella algae & YJ06114 & EN \\
\hline Bacillus subtilis & Bs-1 & $\mathrm{ZSU}$ \\
\hline Lactobacillus plantarum & 8014 & ATCC \\
\hline Staphyloccocus aureus & 6538 & ATCC \\
\hline Salmonella typhimurium & 50115 & GDIM \\
\hline Rhodococcus sp. & NH0578 & EN \\
\hline
\end{tabular}




\section{RESULTS}

\section{Sequence analysis of gyrB gene from Vibrio alginolyticus}

The partial gyrB sequences obtained from Vibrio alginolyticus were aligned, and one consensus sequence was created. There were 54 base substitutions among the $1167 \mathrm{bp}$ homologous gyrB regions of $11 \mathrm{~V}$. alginolyticus strains (Fig. 1). These base substitutions were randomly distributed in the sequences; thus, no obviously variable or conserved regions were observed within the sequences. The sequence heterogeneity was mainly caused by higher base divergence in $V$. alginolyticus ATCC 17749. The gyrB sequences of all $V$. alginolyticus strains shared between 96 and $100 \%$ homology. It should be noted that the strains derived from the same marine environment or animals (e.g. V. alginolyticus NA0419, NA0425, and NA0426) still had different $g y r B$ sequences. The gyrB sequence variation within the $V$. alginolyticus strains, to some degree, indicated the rich genomic polymorphism in $V$. alginolyticus.
Although the gyrB sequences of Vibrio alginolyticus strains were different from each other (but $V$. alginolyticus NA0419 is identical to $V$. alginolyticus DX0406, and V. alginolyticus ZJ0428 is identical to $V$. alginolyticus ZJ0479), the deduced gyrB amino acid sequences of $9 \mathrm{~V}$. alginolyticus strains isolated were identical with the sequence of $V$. alginolyticus 12G01 (AAPS01000042) released in GenBank. However, compared with other strains, V. alginolyticus ATCC 17749 had 21 amino acid variations among the 388 amino acids predicted from the $g y r B$ partial sequences (Fig. 2).

All the gyrB sequences of Vibrio alginolyticus identified by BLAST searches (including the sequences released by us) and some related sequences were used for construction of a phylogenetic tree (Fig. 3). All the $V$. alginolyticus strains were grouped into one strongly supported cluster. The gyrB-based phylogenetic tree indicated that $V$. alginolyticus and $V$. harveyi had the closest phylogenetic relationship, but the similarity values were still lower than $88.4 \%$. Additionally, all sequences from the same species were grouped into one branch, except for V. harveyi LB5 and V. campbel-

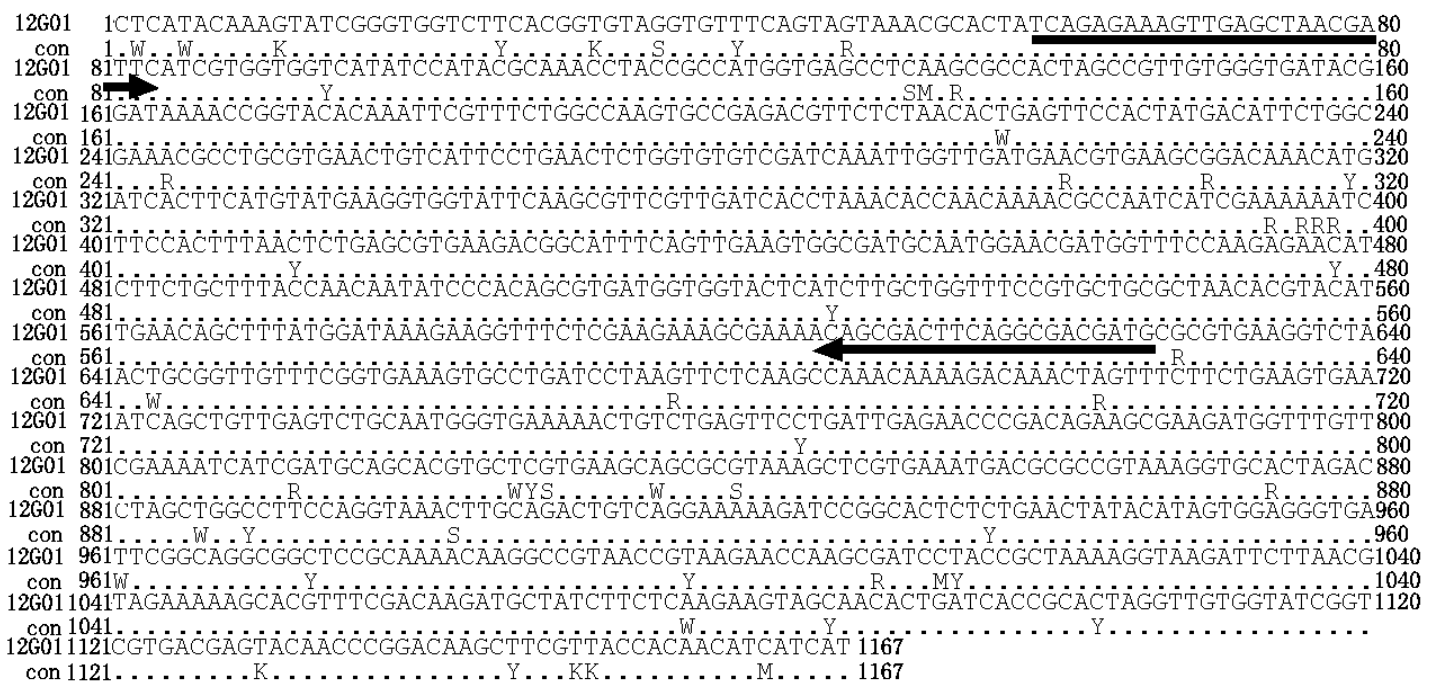

Fig. 1. Vibrio alginolyticus. gyrB sequence comparison of $V$. alginolyticus 12G01 and consensus sequence (con) derived from alignment of $11 \mathrm{~V}$. alginolyticus strains. Variable base sites are shown with letters in consensus sequence. Primer AlgF1: forward black arrow; primer AlgR1: reverse black arrow

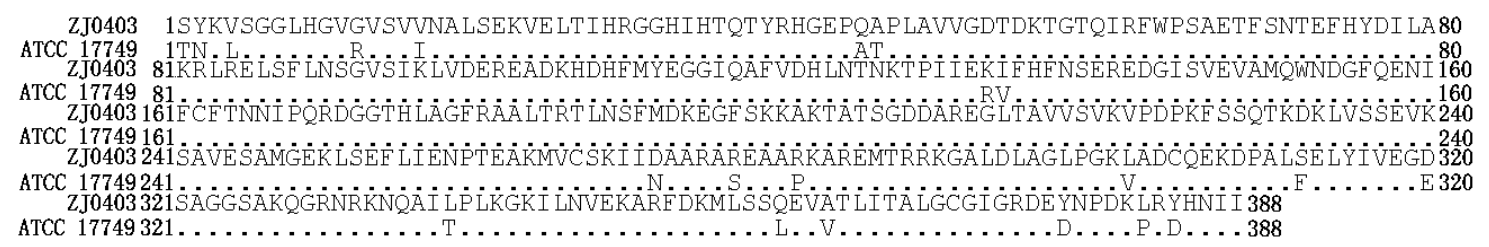

Fig. 2. Vibrio alginolyticus. Comparison of gyrB amino acid sequences from V. alginolyticus ZJ0403 and ATCC 17749. Different amino acid sites are shown with letters in the sequence of $V$. alginolyticus ATCC 17749 


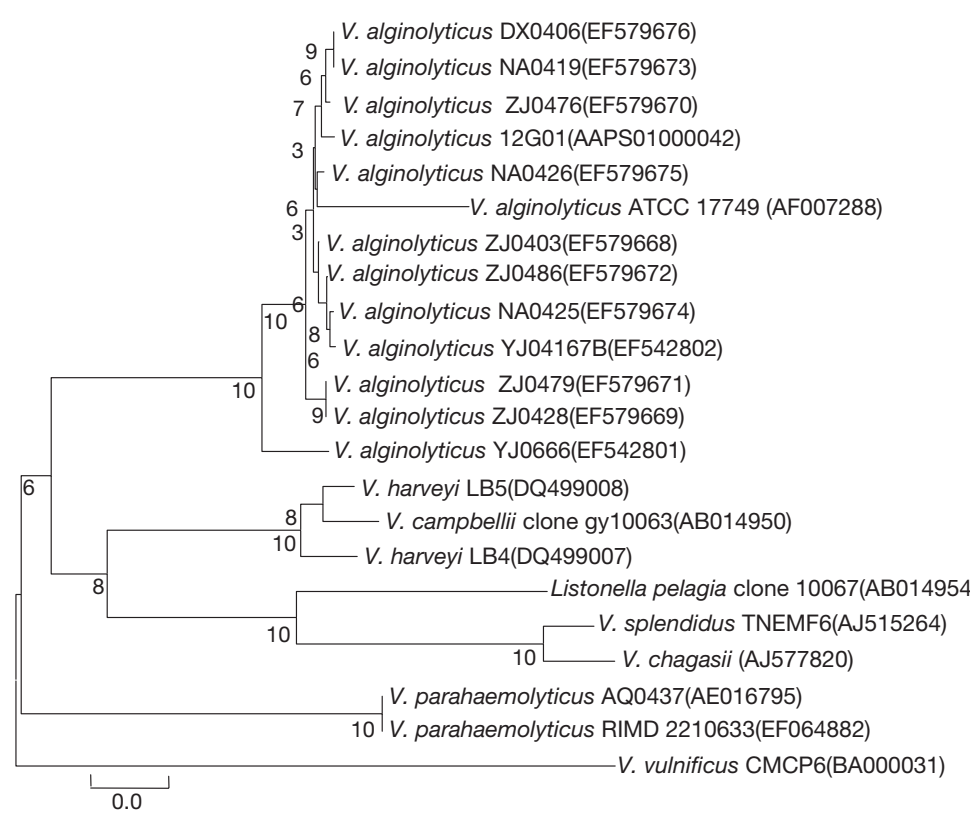

Fig. 3. gyrB sequence-based phylogenetic tree constructed by neighborjoining method. Bootstrap values were obtained after 1000 repetitions. Scale bar indicates $1 \%$ sequence dissimilarity. V: Vibrio

lii clone gy10063 (Fig. 3). The higher divergence of gyrB and the agreement between phenotype and genotype, based on $g y r B$ sequence, demonstrate that the $g y r B$ gene might be an alternative marker to the 16S rRNA gene for phylogeny or molecular identification in Vibrio species.

\section{PCR assay for primer specificity}

By BLAST searches, we found there were no complete matches (especially at 3 ' end of each primer) with other Vibrio species for both primers AlgF1 and AlgR1. Of all 52 bacterial strains tested, only $V$. alginolyticus strains gave rise to positive amplification and produced a predicted 568 bp fragment (Figs. 4 \& 5). No non-specific fragments were amplified, which was demonstrated by electrophoresis of PCR products.

\section{PCR identification of Vibrio alginolyticus from environmental isolates}

Fifty environmental bacterial strains (randomly selected) were screened using Vibrio alginolyticusspecific PCR. Thirty-seven of those strains produced predicted $568 \mathrm{bp}$ PCR fragments (74\% occurrence rate), indicating that they were likely to be $V$. alginolyticus. Subsequent biochemical identification of these 50 strains demonstrated that the strains that gave positive amplification were biochemically identified as $V$. alginolyticus, while the strains that gave no amplification were biochemically identified as other Vibrio or non-Vibrio species (Table 2).

Two PCR-positive strains, YJ0666 and YJ167B, which were biochemically identified as Vibrio alginolyticus, were randomly selected for gyrB sequencing. BLAST searches showed that $g y r B$ sequences of both strains had highest identity values with $V$. alginolyticus strains (>96\%). They were grouped into the cluster on the phylogenetic tree containing all the other $V$. alginolyticus strains, which were obviously distinguishable from the clusters formed by other Vibrio species (Fig. 3). In this cluster, the gyrB sequences of the strain YJ0666 and V. alginolyticus ATCC 17749 had the lowest similarity value, but was still above $96 \%$. According to Thompson \& Swings (2006), in Vibrio species, the strains of the same species would have $>94 \%$ gyrB similarity. Thus, based on gyrB sequences, 11 sequenced strains (including the strains YJ0666 and YJ167B) should belong to $V$. alginolyticus. The above results confirmed the identification accuracy of $V$. alginolyticus-specific PCR. Additionally, the fact that 37 of 50 bacterial strains were identified as $V$. alginolyticus by PCR suggests the prevalence of this species in the marine farming environment is high.

\section{DISCUSSION}

Comparison of 16S rRNA gene sequences has been the 'gold standard' in bacterial molecular systematics (Woese 1987, Vandamme et al. 1996), and many species-specific PCR identifications were developed

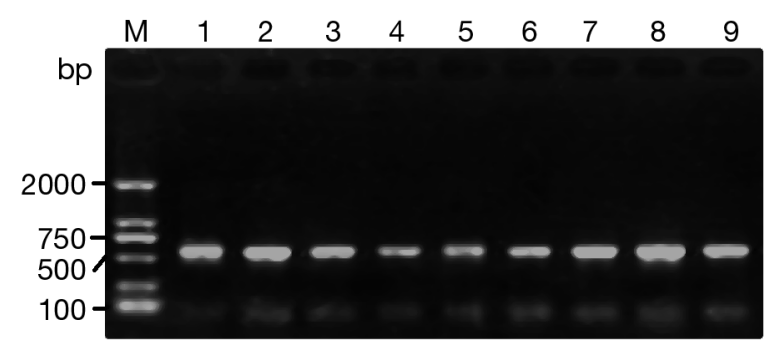

Fig. 4. Vibrio alginolyticus. Agarose electrophoresis of 9 $V$. alginolyticus strains used for gyrB sequencing and primer design. Predicted amplification fragments were 568 bp in length. Lane M: molecular marker; lane 1: $V$. alginolyticus ZJ0403; lane 2: ZJ0428; lane 3: ZJ0476; lane 4: ZJ0479; lane 5: ZJ0486; lane 6: DX0406; lane 7: NA0419; lane 8: NA0425; lane 9: NA0426 


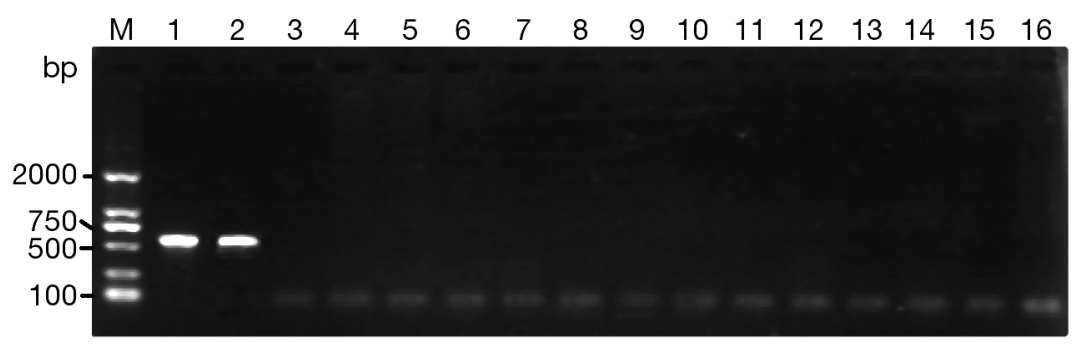

Fig. 5. Typical agarose electrophoresis of PCR products from Vibrio alginolyticus and other bacteria. Lane M: molecular marker; lane 1: V. alginolyticus 0391; lane 2: $V$. alginolyticus 1.1587; lane 3: V. parahaemolyticus ATCC 17802; lane 4: $V$. mimicus 1.1969; lane 5: V. fluvialis 1.1609; lane 6: V. nereis 1.1623; lane 7: $V$. splendidus 1.1606; lane 8: V. pelagius1.1588; lane 9: V. vulnificus 1.1758; lane 10: $V$. natriegens 1.1594; lane 11: $V$. campbellii 1.5997; lane 12: $V$. harveyi 1.1593; lane 13: Non-O1 V. cholerae 06153; lane 14: Listonella anguillarum 0387; lane 15: Shewanella algae YJ06114; lane 16: Pseudomonas fluorescens ATCC 10646

based on this gene. However, for closely related bacterial species, such as those from the genera Vibrio (KitaTsukamoto et al. 1993, Ruimy et al. 1994, Thompson \& Swings 2006), Pandoraea (Coenye \& LiPuma 2002), Bacillus (Yamada et al. 1999, La Duc et al. 2004), Aeromonas (Tacão et al. 2005), Gordonia (Shen et al. 2006), and Mycobacterium (Goh et al. 2006), it lacks sufficient differentiation ability. Therefore, alternative markers for phylogeny and molecular identification have been exploited; specifically, gyrB has shown superiority in this level of species differentiation (Tacão et al. 2005, La Duc et al. 2004, Demarta et al. 2004, Kumar et al. 2006). In the present study, high gyrB homology within $V$. alginolyticus and obvious genetic distances among different Vibrio species also revealed that gyrB could be a better phylogenetic marker for Vibrio. The gyrB gene has also been used for PCR identification of Vibrio species (Kasai et al. 1998, Venkateswaran et al. 1998, Vuddhakul et al. 2000, Kumar et al. 2006, Thaithongnum et al. 2006). The gyrB-based PCR identification of $V$. alginolyticus in the present study and the PCR methods for identification of other Vibrio species indicate gyrB could be a potential candidate for molecular identification of Vibrio species.

Although many base variations in gyrB sequences of Vibrio alginolyticus strains exist, deduced amino acid sequences of all the strains isolated were completely consistent with that of $V$. alginolyticus 12G01 (AAPS01000042) released in GenBank with the excep-

Table 2. Vibrio alginolyticus-specific PCR and biochemical identification of 50 environmental bacterial isolates. Positive (+) and negative (-) amplification by specific PCR

\begin{tabular}{|c|c|c|c|c|c|}
\hline Isolates & Biochemical identification & $\begin{array}{c}\text { Specific } \\
\text { PCR }\end{array}$ & Isolates & Biochemical identification & $\begin{array}{c}\text { Specific } \\
\text { PCR }\end{array}$ \\
\hline A0505 & Vibrio sp. & - & E06125 & V. alginolyticus & + \\
\hline A0508 & Photobacterium damselae & - & E06131 & V. alginolyticus & + \\
\hline A0517 & $V$. alginolyticus & + & E06159 & Shewanella sp. & - \\
\hline A0529 & $V$. alginolyticus & + & E06161 & $V$. alginolyticus & + \\
\hline A0532 & $V$. alginolyticus & + & E06165 & $V$. parahaemolyticus & - \\
\hline A0548 & $V$. alginolyticus & + & YJ167B & $V$. alginolyticus & + \\
\hline E06001 & V. alginolyticus & + & E06169 & V. alginolyticus & + \\
\hline E06011 & V. parahaemolyticus & - & E06172 & V. campbellii & - \\
\hline E06012 & V. alginolyticus & + & E06180 & V. alginolyticus & + \\
\hline E06019 & $V$. alginolyticus & + & E06181 & $V$. alginolyticus & + \\
\hline E06020 & $V$. alginolyticus & + & E06197 & $V$. alginolyticus & + \\
\hline E06024 & Shewanella sp. & - & E06206 & V. cholerae & - \\
\hline E06041 & $V$. alginolyticus & + & E06208 & V. alginolyticus & + \\
\hline E06045 & V. alginolyticus & + & E06214 & Aeromonas hydrophila & - \\
\hline E06047 & $V$. alginolyticus & + & E06229 & $V$. alginolyticus & + \\
\hline E06052 & V. alginolyticus & + & E06234 & $V$. alginolyticus & + \\
\hline E06057 & $V$. alginolyticus & + & E06237 & V. campbellii & - \\
\hline E06064 & V. alginolyticus & + & E06249 & V. alginolyticus & + \\
\hline YJ0666 & V. alginolyticus & + & E06256 & V. alginolyticus & + \\
\hline E06074 & $V$. alginolyticus & + & E06263 & $V$. alginolyticus & + \\
\hline E06075 & $V$. alginolyticus & + & E06266 & $V$. alginolyticus & + \\
\hline E06090 & $V$. alginolyticus & + & E06268 & $V$. alginolyticus & + \\
\hline E06096 & $V$. alginolyticus & + & E06274 & $V$. alginolyticus & + \\
\hline E06117 & V. harveyi & - & E06280 & V. alginolyticus & + \\
\hline E06119 & Proteus mirabilis & - & E06286 & V. harveyi & - \\
\hline
\end{tabular}


tion of $V$. alginolyticus ATCC 17749, whose amino acid sequence has 21 variable sites, compared with other $V$. alginolyticus strains. This might reflect true differences in amino acid sequences in the same species or sequencing mistakes due to unperfected technology at that time (the gyrB sequence of $V$. alginolyticus ATCC 17749 was published in 1998).

The relatively high heterogeneity of $g y r B$ sequences within Vibrio alginolyticus strains indicates that when we design gyrB-based species-specific primers, multiple sequences within the same species should be available and aligned to allow design of primers to the conserved regions of specific species. Otherwise, false negative results may occur in follow-up PCR identification. On the other hand, the relatively high variation of gyrB sequences among $V$. alginolyticus strains (even isolated from the same animal) laterally reflect the genomic polymorphism of $V$. alginolyticus, which was previously confirmed by several studies (Vandenberghe et al. 1999, Zanetti et al. 1999, Chen et al. 2002, Sudheesh et al. 2002).

A high frequency of occurrence (74\%) of Vibrio alginolyticus among isolated bacterial strains, as determined by the screening of $V$. alginolyticus using PCR following biochemical identification, demonstrates the high prevalence of $V$. alginolyticus in the marine farming environment. The prevalence level found here is in accordance with other investigations (Barbieri et al. 1999, Vandenberghe et al. 1999, Baffone et al. 2000); thus, there is a potential hazard of a vibriosis outbreak caused by $V$. alginolyticus, though we currently know little about the pathogenesis of the bacterium.

In summary, we sequenced and analyzed fragments of gyrB gene from Vibrio alginolyticus, and developed a gyrB-based PCR method for rapid identification and screening of $V$. alginolyticus from environmental bacterial isolates. Results indicate that the $g y r B$ gene is a good marker for molecular identification of $V$. alginolyticus.

Acknowledgements. This work was funded by the National Basic Research Programme of China (no. 2006CB101803) and the Natural Science Fund of China (no. 30700016).

\section{LITERATURE CITED}

Altschul SF, Gish W, Miller W, Myers EW, Lipman DJ (1990) Basic local alignment search tool. J Mol Biol 215:403-410

Baffone W, Pianetti A, Bruscolini F, Barbieri E, Citterio B (2000) Occurrence and expression of virulence-related properties of Vibrio species isolated from widely consumed seafood products. Int J Food Microbiol 54:9-18

Balebona MC, Andreu MJ, Bordas MA (1998) Pathogenicity of Vibrio alginolyticus for cultured gilt-head sea bream (Sparus aurata L.). Appl Environ Microbiol 64:4269-4275

Barbieri E, Falzano L, Fiorentini C, Pianetti A, Baffone W, Fabbri A (1999) Occurrence, diversity, and pathogenicity of halophilic Vibrio spp. and non-01 Vibrio cholerae from estuarine waters along the Italian Adriatic coast. Appl Environ Microbiol 65:2748-2753

Brenner DJ, Krieg NR, Staley JR (2005) Bergey's manual of systematic bacteriology, Vol 2, Part B, 2nd edn. Springer, New York

Chen C, Hu CQ, Zhang LP (2002) DNA polymorphism of Vibrio alginolyticus isolated from culture environment, diseased fish and penaeid shrimps. J Trop Oceanogr 21:49-54

Coenye T, LiPuma J (2002) Use of the gyrB gene for the identification of Pandoraea species. FEMS Microbiol Lett 208:15-19

Daniels NA, Shafaie A (2000) A review of pathogenic Vibrio infections for clinicians. Infect Med 17:665-685

Demarta A, Respinis S, Dolina M, Peduzzi R (2004) Molecular typing of Yersinia frederiksenii strains by means of $16 \mathrm{~S}$ rDNA and gyrB genes sequence analyses. FEMS Microbiol Lett 238:423-428

Di Pinto A, Ciccarese G, Tantillo G, Catalano D, Forte VT (2005) A collagenase-targeted multiplex PCR assay for identification of Vibrio alginolycticus, Vibrio cholerae, and Vibrio parahaemolyticus. J Food Prot 68:150-153

> Fukushima M, Kakinuma K, Kawaguchi R (2002) Phylogenetic analysis of Salmonella, Shigella, and Escherichia coli strains on the basis of the gyrB gene sequence. J Clin Microbiol 40:2779-2785

Goh KS, Fabre M, Huard RC, Schmid S, Sola C, Rastogi N (2006) Study of the gyrB gene polymorphism as a tool to differentiate among Mycobacterium tuberculosis complex subspecies further underlines the older evolutionary age of 'Mycobacterium canettii'. Mol Cell Probes 20: $182-190$

Izumi S, Fujii H, Aranishi F (2005) Detection and identification of Flavobacterium psychrophilum from gill washings and benthic diatoms by PCR-based sequencing analysis. J Fish Dis 28:559-564

Izumi S, Yamamoto M, Suzuki K, Shimizu A (2007) Identification and detection of Pseudomonas plecoglossicida isolates with PCR primers targeting the gyrB region. J Fish Dis 30:391-397

> Kasai H, Watanabe K, Gasteiger E, Bairoch A, Isono K, Yamamoto S, Harayama S (1998) Construction of the gyrB database for the identification and classification of bacteria. Genome Inform Ser Workshop Genome Inform 9:13-21

Kita-Tsukamoto K, Lyalzu H, Nanbe K, Simidu U (1993) Phylogenetic relationships of marine bacteria, mainly members of the family Vibrionaceae, determined on the basis of 16S rRNA sequences. Int J Syst Bacteriol 43:8-19

Kumar HS, Parvathi A, Karunasagar I, Karunasagar I (2006) A gyrB-based PCR for the detection of Vibrio vulnificus and its application for direct detection of this pathogen in oyster enrichment broths. Int J Food Microbiol 111:216-220

La Duc MT, Satomi M, Agata N, Venkateswaran K (2004) gyrB as a phylogenetic discriminator for members of the Bacillus anthracis-cereus-thuringiensis group. J Microbiol Methods 56:383-394

> Liu CH, Cheng W, Hsu JP, Chen JC (2004) Vibrio alginolyticus infection in the white shrimp Litopenaeus vannamei confirmed by polymerase chain reaction and 16S rDNA sequencing. Dis Aquat Org 61:169-174

Nhung PH, Ohkusu K, Miyasaka J, Sun XS, Ezaki T (2007) Rapid and specific identification of 5 human pathogenic Vibrio species by multiplex polymerase chain reaction targeted to dnaJ gene. Diagn Microbiol Infect Dis 59: 271-275

O'Hara CM, Sowers EG, Bopp CA, Duda SB, Strockbine NA (2003) Accuracy of six commercially available systems for 
identification of members of the family Vibrionaceae. J Clin Microbiol 41:5654-5659

Robert-Pillot A, Guenole A, Fournier JM (2002) Usefulness of R72H PCR assay for differentiation between Vibrio parahaemolyticus and Vibrio alginolyticus species: validation by DNA-DNA hybridization. FEMS Microbiol Lett 215: $1-6$

Ruimy R, Breittmayer V, Elbaxe P, Lafay B, Boussemart O, Gauthier M (1994) Phylogenetic analysis and assessment of the genera Vibrio, Photobacterium, Aeromonas, and Plesiomonas deduced from small-subunit rRNA sequences. Int J Syst Bacteriol 44:416-426

Sen K (2005) Development of a rapid identification method for Aeromonas species by multiplex-PCR. Can J Microbiol 51:957-966

Shen FT, Lu HL, Lin JL, Huang WS, Arun AB, Young CC (2006) Phylogenetic analysis of members of the metabolically diverse genus Gordonia based on proteins encoding the gyrB gene. Res Microbiol 157:367-375

Slack AT, Symonds ML, Dohnt MF, Smythe LD (2006) Identification of pathogenic Leptospira species by conventional or real-time PCR and sequencing of the DNA gyrase subunit B encoding gene. BMC Microbiol 6:95-104

Sudheesh PS, Kong J, Xu HS (2002) Random amplified polymorphic DNA-PCR typing of Vibrio parahaemolyticus and $V$. alginolyticus isolated from cultured shrimps. Aquaculture 207:11-17

Tacão M, Moura A, Henriques I, Savedra MJ, Correia A (2005) Evaluation of 16S rDNA- and gyrB-DGGE for typing members of the genus Aeromonas. FEMS Microbiol Lett 246:11-18

Thaithongnum S, Ratanama P, Weeradechapol K, Sukhoom A, Vuddhakul V (2006) Detection of V. harveyi in shrimp postlarvae and hatchery tank water by the most probable number technique with PCR. Aquaculture 261:1-9

Thompson FL, Swings J (2006) Taxonomy of vibrios. In: Thompson FL, Austin B, Swings J, Nishibuchi M (eds) The biology of vibrios. ASM Press, Washington, DC

Thompson FL, Lida T, Swings J (2004) Biodiversity of vibrios. Microbiol Mol Biol Rev 68:403-431

- Vandamme P, Pot B, Gillis M, Vos P, Kersters K, Swings J (1996) Polyphasic taxonomy, a consensus approach to bac-

Editorial responsibility: Catherine Collins, Aberdeen, UK terial systematics. Microbiol Rev 60:407-438

> Vandenberghe J, Verdonck L, Robles-Arozarena R, Rivera G, Bolland A, Balladares M (1999) Vibrios associated with Litopenaeus vannamei larvae, postlarvae, broodstock, and hatchery probionts. Appl Environ Microbiol 65:2592-2597

- Venkateswaran K, Dohmoto N, Harayama S (1998) Cloning and nucleotide sequence of the gyrB gene of Vibrio parahaemolyticus and its application in detection of this pathogen in shrimp. Appl Environ Microbiol 64:681-687

Villamil L, Fgueras A, Planas M, Novoa B (2003) Control of Vibrio alginolyticus in Artemia culture by treatment with bacterial probiotics. Aquaculture 219:43-56

Vuddhakul V, Nakai T, Matsumoto C, Oh T, Nishino T, Chen $\mathrm{CH}$ (2000) Analysis of gyrB and toxR gene sequences of Vibrio hollisae and development of gyrB- and toxR-targeted PCR methods for isolation of $V$. hollisae from the environment and its identification. Appl Environ Microbiol 66:3506-3514

Wang FX, Zhou H, Ling H, Zhou HZ, Liu WH, Shao YM, Zhou $\mathrm{J}$ (2007) Subtype and sequence analysis of HIV-1 strains in Heilongjiang Province. Chin Med J 120:2006-2010

Woese CR (1987) Bacterial evolution. Microbiol Rev 51: 221-271

Yamada S, Ohashi E, Agata N, Venkateswaran K (1999) Cloning and nucleotide sequence analysis of $g y r B$ of Bacillus cereus, B. thuringiensis, B. mycoides, and $B$. anthracis and their application to the detection of $B$. cereus in rice. Appl Environ Microbiol 65:1483-1490

> Yamamoto S, Harayama S (1995) PCR amplification and direct sequencing of $g y r B$ genes with universal primers and their application to the detection and taxonomic analysis of Pseudomonas putida strains. Appl Environ Microbiol 61:1104-1109

Zanetti S, Deriu A, Duprè I, Sanguinetti M, Fadda G, Sechi LA (1999) Differentiation of Vibrio alginolyticus strains isolated from Sardinian waters by ribotyping and a new rapid PCR finger printing method. Appl Environ Microbiol 65: 1871-1875

Zhou S, Hou Z, Li N, Qin Q (2007) Development of a SYBR Green I real-time PCR for quantitative detection of Vibrio alginolyticus in seawater and seafood. J Appl Microbiol 103:1897-1906

Submitted: March 10, 2008; Accepted: September 16, 2008 Proofs received from author(s): September 26, 2008 